\title{
Open-Source Technology for Real-Time Continuous Glucose Monitoring in the Neonatal Intensive Care Unit: Case Study in a Neonate With Transient Congenital Hyperinsulinism
}

Katarina Braune ${ }^{1,2}$, MD; Mandy Wäldchen ${ }^{3}$, MSc; Klemens Raile ${ }^{1}$, MD; Sigrid Hahn ${ }^{4}$, MD; Tebbe Ubben ${ }^{5}$; Susanne Römer $^{4}$, MD; Daniela Hoeber ${ }^{6}$, MD; Nora Johanna Reibel ${ }^{4}$, MD; Michael Launspach ${ }^{2,4}$, MD; Oliver Blankenstein ${ }^{7,8}$, MD; Christoph Bührer ${ }^{4}$, MD

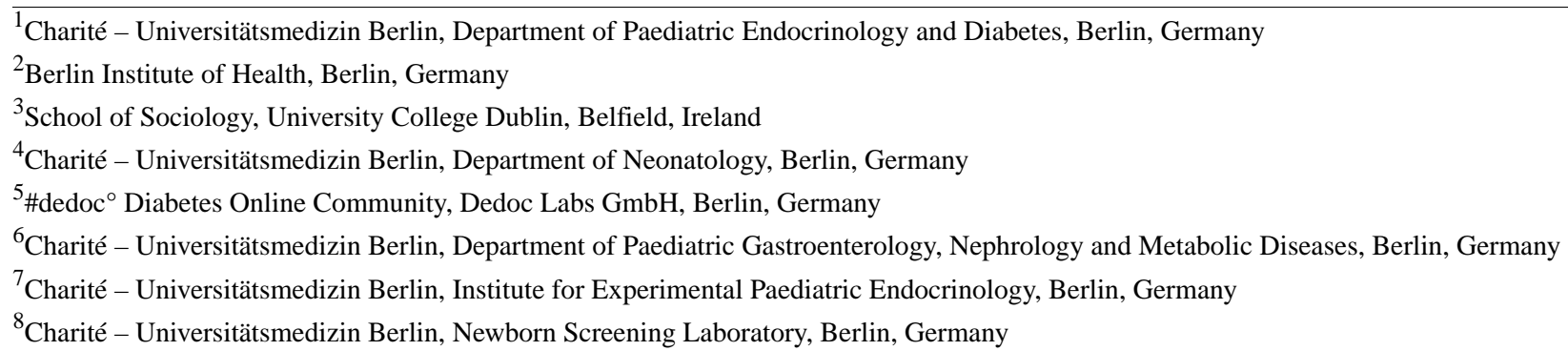

Corresponding Author:

Katarina Braune, MD

Charité - Universitätsmedizin Berlin

Department of Paediatric Endocrinology and Diabetes

Augustenburger Platz 1

Berlin, 13353

Germany

Phone: 4930450616454

Email: katarina.braune@charite.de

\begin{abstract}
Background: Use of real-time continuous glucose monitoring (rtCGM) systems has been shown to be a low-pain, safe, and effective method of preventing hypoglycemia and hyperglycemia in people with diabetes of various age groups. Evidence on rtCGM use in infants and in patients with conditions other than diabetes remains limited.

Objective: This case study describes the off-label use of rtCGM and the use of an open-source app for glucose monitoring in a newborn with prolonged hypoglycemia secondary to transient congenital hyperinsulinism during the perinatal period.

Methods: The Dexcom G6 rtCGM system (Dexcom, Inc) was introduced at 39 hours of age. Capillary blood glucose checks were performed regularly. In order to benefit from customizable alert settings and detect hypoglycemic episodes, the open-source rtCGM app xDrip+ was introduced at 9 days of age.

Results: Time in range ( $45-180 \mathrm{mg} / \mathrm{dL})$ for interstitial glucose remained consistently above $90 \%$, whereas time in hypoglycemia ( $<45 \mathrm{mg} / \mathrm{dL}$ ) decreased. Mean glucose was maintained above $70 \mathrm{mg} / \mathrm{dL}$ at 72 hours of life and thereafter. Daily sensor glucose profiles showed cyclic fluctuations that were less pronounced over time.

Conclusions: While off-label use of medication is both common practice and a necessity in newborn infants, there are few examples of off-label uses of medical devices, rtCGM being a notable exception. Real-time information allowed us to better understand glycemic patterns and to improve the quality of glycemic control accordingly. Severe hypoglycemia was prevented, and measurement of serum levels of insulin and further lab diagnostics were performed much faster, while the patient's individual burden caused by invasive procedures was reduced. Greater customizability of threshold and alert settings would be beneficial for user groups with glycemic instability other than people with diabetes, and for hospitalized newborn infants in particular. Further research in the field of personal and off-label rtCGM use, efficacy studies evaluating the accuracy of low glucose readings, and studies on the differences between algorithms in translating raw sensor data, as well as customization of commercially available rtCGM systems, is needed.
\end{abstract}


(J Med Internet Res 2020;22(12):e21770) doi: 10.2196/21770

\section{KEYWORDS}

open-source; mobile health; continuous glucose monitoring; off-label use; neonatal hypoglycemia; congenital hyperinsulinism; transient hyperinsulinism

\section{Introduction}

Transient and persistent congenital hyperinsulinism (CHI) are rare diseases affecting 1 to 2 in 50,000 newborns. At least 12 genetic defects have been identified that result in dysregulated and increased insulin secretion and subsequently severe hypoglycemia, which may be transient or persistent $[1,2]$. Frequent hypoglycemia is a potentially life-threatening complication of CHI and may lead to permanent brain damage, which may present in developmental delay and mild to severe neurocognitive difficulties such as deficits in attention, memory, and visual and sensorimotor functions in children with $\mathrm{CHI}$ $[3,4]$. Furthermore, prolonged hospitalizations and intense medical regimes pose a constant psychological burden to infants and children with $\mathrm{CHI}$ and their caregivers, limiting their participation in social life, kindergarten, and school [2,5]. Therefore, prevention of hypoglycemia is the main treatment goal in patients with CHI [5,6]. Therapeutic regimens are complex and depend on the underlying genotype and phenotype. Treatment options today include regular feeding, pharmacotherapy with diazoxide, somatostatin analogues and glucagon for diffuse forms, and surgery for focal variants of CHI [6].

Real-time continuous glucose monitoring (rtCGM) and intermittently scanned continuous glucose monitoring (isCGM), as designed for and commonly used by people with diabetes, provide information on current interstitial glucose levels and trends, and alert the user of current or predicted hypoglycemia and hyperglycemia as well as rapid changes in glucose levels. With regular measurements up to every 5 minutes, they also provide statistics on time spent in hypoglycemia, in hyperglycemia, and within range.

Evidence on rtCGM use for glycemic management in neonates is limited, and there is no evidence of calibration-free rtCGM systems in infants so far. Benefits with respect to glycemic control [7] and less procedural pain [8] have been previously described for very low-birth-weight preterm infants in a feasibility study. Furthermore, a study found continuous tissue glucose monitoring to be helpful to identify infants at risk for metabolic instabilities [9]. However, knowledge remains limited for infants and other patient groups at risk of hypoglycemia so far $[10,11]$.

The off-label use of rtCGM in children with CHI was first described in 2004 [12]. Further studies describe rtCGM and isCGM as safe, effective, convenient, and less painful methods of glucose monitoring in CHI patients that provide helpful information for therapeutic decisions [13,14]. Caregivers found the indication of glucose trends to be helpful, felt more confident in everyday management of the condition, and felt less worried about the occurrence of asymptomatic hypoglycemia [12,14]. However, older rtCGM/isCGM systems were reported to have limited accuracy, especially for hypoglycemic levels, and therefore not recommended to completely replace capillary blood glucose (CBG) testing, but rather seen as an adjunctive, beneficial therapy $[13,15]$.

To our knowledge, this case study describes the first use of the rtCGM app xDrip+ in a hospital and intensive care unit (ICU) setting and the first off-label use of rtCGM in a newborn with severe hypoglycemia secondary to transient $\mathrm{CHI}$ soon after birth.

\section{Methods}

\section{Clinical Case}

A male infant was delivered full term with a birth weight of 3575 g. An emergency cesarean delivery was performed in response to fetal heart rate monitoring indicating fetal distress. The infant presented with bradypnea, floppiness, and sporadic myoclonic jerks and was transiently treated with noninvasive positive pressure resuscitation. A CBG level of $12 \mathrm{mg} / \mathrm{dL}$ was detected at 60 minutes of life. Despite feeding attempts and buccal administration of $40 \%$ dextrose gel, the blood glucose level decreased further to $1 \mathrm{mg} / \mathrm{dL}$ at 120 minutes of life. The patient was started on continuous intravenous glucose and admitted to the neonatal intensive care unit (NICU) for further diagnostics and treatment. The continuous intravenous glucose administration required to maintain blood glucose levels above $50 \mathrm{mg} / \mathrm{dL}$ was incrementally increased from $8 \mathrm{mg} / \mathrm{kg} / \mathrm{min}$ to over $18 \mathrm{mg} / \mathrm{kg} / \mathrm{min}$. This required placement of a central venous line at 37 hours of age to allow for administration of hypertonic glucose solutions. In addition, the infant received copious enteral feedings.

The child's father and the paternal uncle were both reported to have experienced transient postnatal hypoglycemia, requiring hospitalization for 3 weeks after birth. The child's father reported having often experienced mild hypoglycemia symptoms such as hunger and craving for sweets when fasting. However, blood glucose levels were reported to be within normal range during routine checkups as an adult. There was no history of diabetes in either of the parents, and screening for gestational diabetes during pregnancy was reported to be negative. However, the paternal grandmother was reported to have been diagnosed with type 1 diabetes at 7 years of age.

\section{Genetic Testing}

Next-generation sequencing (quality level type A; SureSelect XT, Custom Constitutional Panel $17 \mathrm{Mb}$; Agilent Technologies, Inc) of a CHI panel, including ABCC8 (GenBank NM_000352.4), HADH (GenBank NM_005327.4), HNF4A (GenBank NM_175914.4), KCNJ11 (GenBank NM_000525.3), KMT2D (GenBank NM_003482), and UCP2 (GenBank NM_003355.2), was performed by Labor Berlin, Germany. 


\section{Real-Time Glucose Monitoring}

To reduce the frequency of capillary blood samples and estimate the right moment for further lab diagnostics, the Dexcom G6 rtCGM system (Dexcom, Inc) was introduced for off-label use at 39 hours of age. In addition, CBG checks were performed regularly, at least 3 times per day (Multimedia Appendix 1). All decisions concerning the therapeutic regimen were based on confirmatory CBG tests. Sensors were placed at the lateral sides of thighs or upper arms (Figures 1 and 2) where enough fat and muscle tissue were present. Sensors were replaced every 7 days.
During the first week, the sensor was paired with a Dexcom G6 handheld device with customizable alert settings; however, the urgent low glucose alarm threshold at a glucose level of 55 $\mathrm{mg} / \mathrm{dL}$, which was frequently passed in this neonate but does not meet the requirements in neonates within the first week of life, could not be further reduced. Furthermore, glucose levels below $40 \mathrm{mg} / \mathrm{dL}$ could not be further differentiated. In order to benefit from customizable alert settings and include potential hypoglycemic levels below $40 \mathrm{mg} / \mathrm{dL}$, the informed decision was made to pair the sensors with the caregivers' personal Android phone using the app xDrip+.

Figure 1. Upper thigh as a suitable rtCGM application site in neonates.

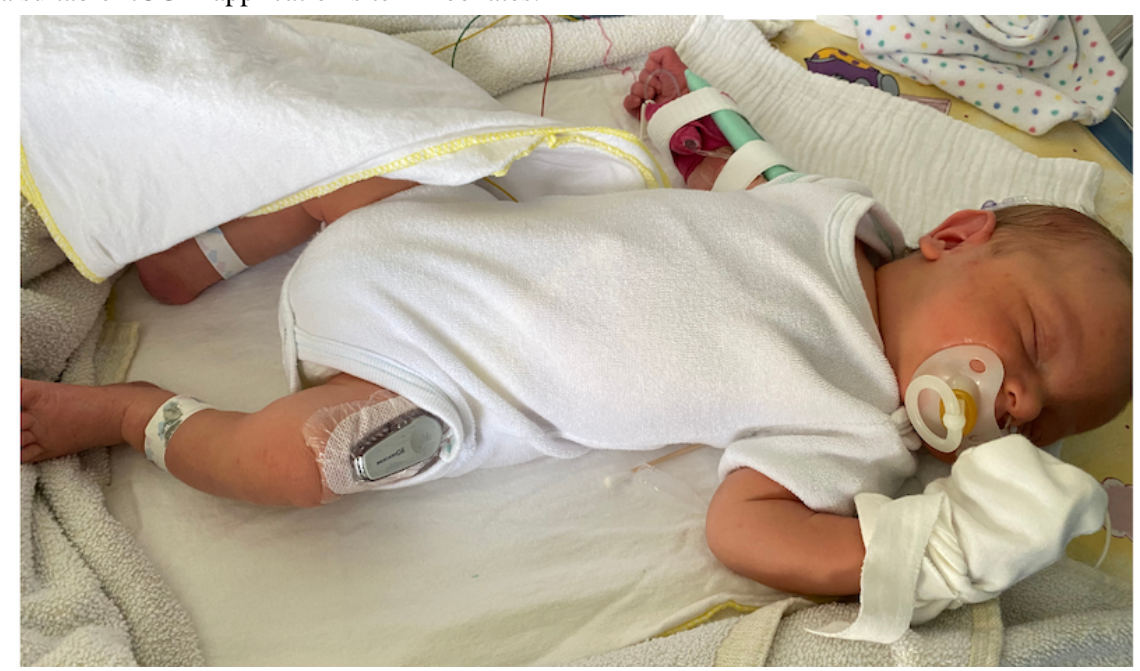

Figure 2. Upper arm as a suitable rtCGM application site in neonates.

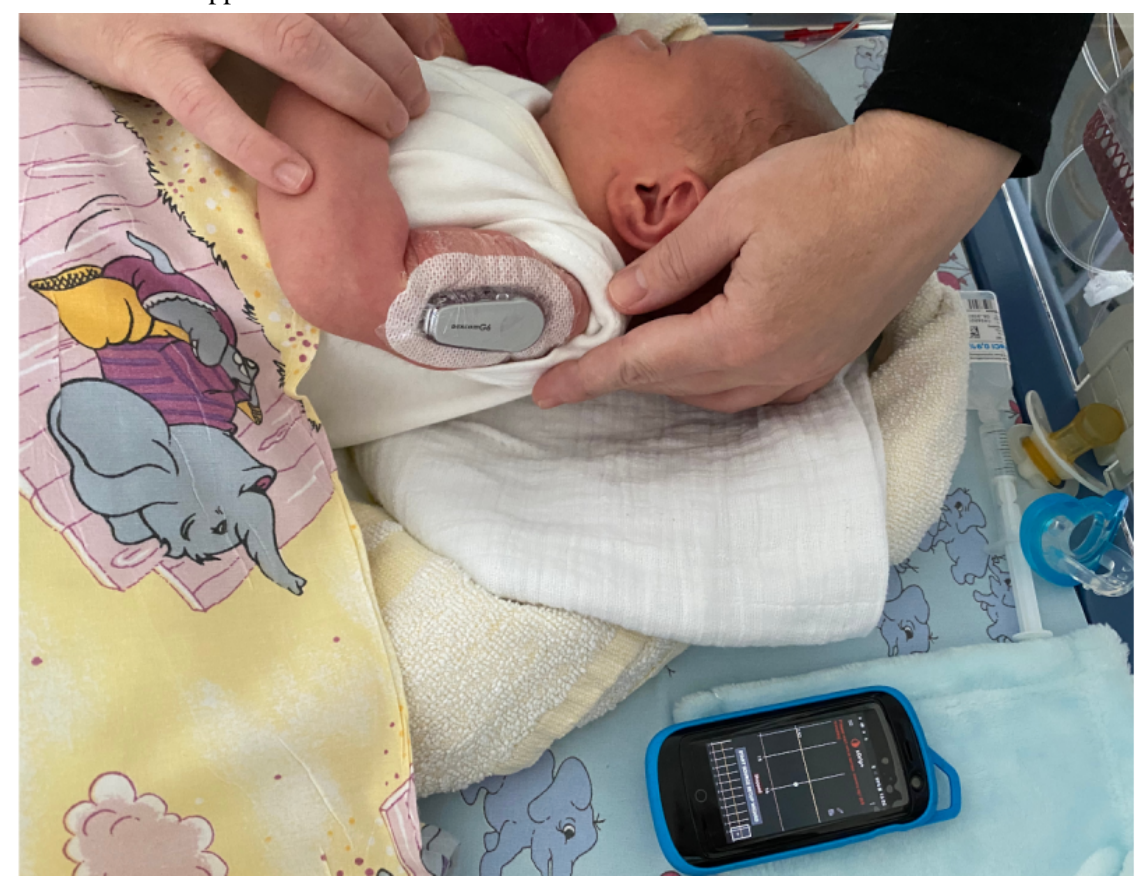

\section{Specifics of the xDrip+ Algorithm}

$\mathrm{xDrip}+[16]$ is an open-source product with no regulatory approval that allows the user to choose between the approved native algorithm, which runs on the Dexcom G6 transmitter for translating uncalibrated transmitter data into interstitial glucose level estimations, and its own algorithm, which approximates a linear function using the method of weighted least squares regression by weighting calibration points based on their value, sensor and calibration age, the current glucose trend, a variability heuristic, and other factors. Furthermore, low glucose alarm settings are fully customizable. In this case study, the xDrip+ algorithm was used with a minor modification that allowed sensor glucose levels below $40 \mathrm{mg} / \mathrm{dL}$ to be received, although 
accuracy was expected to be limited in this range. Alerts were set at $45 \mathrm{mg} / \mathrm{dL}$ for low sensor glucose levels and at $140 \mathrm{mg} / \mathrm{dL}$ for high sensor glucose levels.

\section{Data Analysis}

For the first 7 days of sensor data, rtCGM readings were exported from the Dexcom handheld device using the Dexcom Clarity software. For the following days when xDrip+ was used, sensor data was exported through the built-in data export function in the xDrip+ app. For the analysis of sensor data, we computed statistical properties (arithmetic mean and standard deviation) in the programming language Python 3.7. Furthermore, time in hypoglycemia and time in range were calculated as follows:

$$
\begin{aligned}
& \text { Time-in-Hypoglycemia }=\frac{\mathrm{n}[\text { CGM values }<45 \mathrm{mg} / \mathrm{dL}]}{\mathrm{n}_{\text {total }}[\text { CGM values }]} \\
& \text { Time-in-Range }=\frac{\mathrm{n}[45 \mathrm{mg} / \mathrm{dL} \leq \mathrm{CGM} \text { values }<180 \mathrm{mg} / \mathrm{dL}]}{\mathrm{n}_{\text {total }}[\mathrm{CGM} \text { values }]}
\end{aligned}
$$

As there is currently no standardized definition for treatment consequences in response to low and high glucose levels in neonates, but their physiological range tends to be lower than in older individuals [9], sensor glucose in range was defined by a lower threshold of $45 \mathrm{mg} / \mathrm{dL}(2.5 \mathrm{mmol} / \mathrm{L})$ and an upper threshold of $180 \mathrm{mg} / \mathrm{dL}(10 \mathrm{mmol} / \mathrm{L})$. Therefore, time in hypoglycemia was calculated based on sensor readings under $45 \mathrm{mg} / \mathrm{dL}(2.5 \mathrm{mmol} / \mathrm{L})$.

\section{Results}

\section{Diagnostic Workup}

The infant responded well to a single subcutaneous injection of $30 \mu \mathrm{g} / \mathrm{kg}$ of glucagon (GlucaGen Hypokit; Novo Nordisk A/S). Therefore, a glycogen storage disease was unlikely to be the underlying condition and congenital hyperinsulinism was suspected. According to CHI treatment guidelines [6], a continuous subcutaneous glucagon infusion was initiated at 64 hours of age and gradually increased (up to $27.2 \mu \mathrm{g} / \mathrm{kg} / \mathrm{h}$ ) (Multimedia Appendix 1). Glucagon dosage was adjusted (increased or lowered) according to rtCGM glucose using defined thresholds for each action; thus, the continuous glucose infusion could be gradually reduced and completely terminated by 13 days of age. In the following days, glucagon administration was gradually decreased and completely terminated 17 days of age. That treatment algorithm successfully prevented occurrence of any symptomatic hypoglycemia (eg, seizures, hypothermia, hypotonia, bradypnea). No other drugs such as diazoxide or lanreotide were administered.

Initial hypoglycemia screening revealed hyperinsulinemia with no ketonemia present (blood glucose $29 \mathrm{mg} / \mathrm{dL}$, insulin 9.03 $\mathrm{mU} / \mathrm{L}, \mathrm{C}$-peptide $2.34 \mu \mathrm{g} / \mathrm{L}$ ). After terminating the intravenous glucose and the subcutaneous glucagon infusion and with increasing improvement of oral feeding and hence regular and reliable enteral glucose uptake, no new hypoglycemic episodes occurred between days 17 and 20. Consequently, we suspected normalization of insulin secretion, which was substantiated by an analysis after a strict fasting period of 6.5 hours (blood glucose $86 \mathrm{mg} / \mathrm{dL}$, insulin $1.5 \mathrm{mU} / \mathrm{L}, \mathrm{C}$ peptide $0.54 \mu \mathrm{g} / \mathrm{L}$, ketone bodies $0.4 \mathrm{mmol} / \mathrm{L}$ ) on day 20 . With these results, we were able to terminate rtCGM use and discharge the infant on the same day in good health.

Genetic testing did not reveal any disease-relevant pathologic variation in genes that are most frequently associated with $\mathrm{CHI}$ : ABCC8 (GenBank NM_000352.4), HADH (GenBank NM_005327.4), HNF4A (GenBank NM_175914.4), KCNJ11 (GenBank NM_000525.3), and UCP2 (NM_003355.2). However, we detected a novel, highly conserved, and heterozygous missense variant in the KMT2D gene (c.3976C > T, $\mathrm{R} 1326 \mathrm{~W})$, which was interpreted as a pathogenic variant within this analysis and might be causative in this particular case of a Kabuki syndrome with predominantly transient, congenital hyperinsulinism $[17,18]$.

\section{Glycemic Outcomes}

Time in range (sensor glucose readings between 45 and 180 $\mathrm{mg} / \mathrm{dL}$ or 2.5 and $10 \mathrm{mmol} / \mathrm{L}$ ) remained consistent above $90 \%$, whereas time in hypoglycemia $(<45 \mathrm{mg} / \mathrm{dL}$ or $<2.5 \mathrm{mmol} / \mathrm{L})$ decreased, and mean glucose was maintained above $70 \mathrm{mg} / \mathrm{dL}$ or $3.8 \mathrm{mmol} / \mathrm{L}$ at 72 hours of life and after (Table 1). Daily sensor glucose profiles (Multimedia Appendix 1) show cyclic fluctuations exceeding $45 \mathrm{mg} / \mathrm{dL}(2.5 \mathrm{mmol} / \mathrm{L})$ on most days and occasionally $180 \mathrm{mg} / \mathrm{dL}(10 \mathrm{mmol} / \mathrm{L})$. These cyclic fluctuations were found to be less pronounced over time.

rtCGM readings were found to be mostly accurate compared to CBG (Multimedia Appendix 1). Significant deviations (>15\%) occurred within the first 24 hours after a new sensor was placed. After recalibration of the rtCGM, accuracy of rtCGM readings was satisfactory ( $<15 \%$ deviations). 
Table 1. Analysis of rtCGM readings within the first 16 days of life in a neonate with transient CHI, including mean sensor glucose (SD), time in hypoglycemia (defined as the percentage of sensor readings below $45 \mathrm{mg} / \mathrm{dL}$ ), and time in range (defined as the percentage of sensor readings between $45 \mathrm{mg} / \mathrm{dL}$ and $180 \mathrm{mg} / \mathrm{dL})$.

\begin{tabular}{|c|c|c|c|c|c|c|}
\hline Patient age, $d(h)$ & Sensor readings, $\mathrm{n}$ & Glucose, $\mathrm{mg} / \mathrm{dL}$, mean (SD) & Readings in range, $\mathrm{n}$ & $\mathrm{TIR}^{\mathrm{a}}, \%$ & Readings in hypoglycemia, $\mathrm{n}$ & $\mathrm{TIH}^{\mathrm{b}}, \%$ \\
\hline $2(39-48)$ & 74 & $68(16)$ & 71 & 95.9 & 3 & 4.1 \\
\hline $3(49-72)$ & 291 & $69(29)$ & 240 & 82.5 & 51 & 17.5 \\
\hline $4(73-96)$ & 288 & $98(34)$ & 288 & 100.0 & 0 & 0.0 \\
\hline $5(97-120)$ & 290 & $79(16)$ & 286 & 98.6 & 4 & 1.4 \\
\hline $6(121-144)$ & 291 & $82(17)$ & 280 & 96.2 & 11 & 3.8 \\
\hline $7(145-168)$ & 282 & $94(36)$ & 274 & 97.2 & 8 & 2.8 \\
\hline $8(169-192)$ & 287 & $77(21)$ & 270 & 94.1 & 17 & 5.9 \\
\hline $9(193-216)$ & 203 & $85(29)$ & 190 & 93.6 & 13 & 6.4 \\
\hline $10(217-240)$ & 213 & $81(22)$ & 197 & 92.5 & 16 & 7.5 \\
\hline $11(241-264)$ & 284 & $81(25)$ & 261 & 91.9 & 23 & 8.1 \\
\hline $12(265-288)$ & 281 & $86(24)$ & 274 & 97.5 & 7 & 2.5 \\
\hline $13(289-312)$ & 296 & $81(19)$ & 284 & 95.9 & 12 & 4.1 \\
\hline $14(313-336)$ & 288 & $73(20)$ & 265 & 92.0 & 23 & 8.0 \\
\hline $15(337-360)$ & 248 & $72(18)$ & 235 & 94.8 & 13 & 5.2 \\
\hline $16(361-372)$ & 138 & $83(17)$ & 138 & 100.0 & 0 & 0.0 \\
\hline
\end{tabular}

${ }^{\mathrm{a}}$ TIR: time in range.

${ }^{\mathrm{b}} \mathrm{TIH}$ : time in hypoglycemia.

\section{Discussion}

\section{Principal Findings}

This case study describes the use of a Dexcom G6 rtCGM system in a neonate with transient $\mathrm{CHI}$ during the perinatal period, using two different algorithms. The real-time information provided by the rtCGM system allowed us to better understand glycemic patterns of the underlying condition and to improve the quality of glycemic control of our patient accordingly. Severe hypoglycemia was successfully prevented and measurement of serum levels of insulin and further lab diagnostics were performed much faster, while the patient's individual burden caused by invasive procedures could be reduced.

To our knowledge, this is the first report on the use of open-source apps for glucose monitoring such as xDrip+ in a hospital and ICU setting, as well as the first study reporting an off-label use of a precalibrated rtCGM system in a neonate. Furthermore, we described the first use of rtCGM in an infant with transient $\mathrm{CHI}$ in the most critical phase during the first days of life.

While off-label use of medication is both common practice and a necessity in newborn infants, there are few examples of off-label uses of medical devices, rtCGM being a notable exception [7,8,19-24]. CBG tests are the current standard of care in the management of neonatal hypoglycemia. However, CBG has notable limitations. Heel pricks, associated with pain, are required every time a blood sample is taken. Furthermore, it provides only single point measurements without a continuous profile on glucose trends, dynamics, and interactions with drugs and meals. Conversely, rtCGM records any hypoglycemic episode in a quantitative fashion, displays detailed pharmacodynamics of single drugs, and consequently can help to determine a drug's long-term requirement. We assume that rtCGM use could be extremely helpful in any hospital or home setting and in this case, could help reduce the child's risk for neurological long-term complications $[3,4,25]$. Our experiences with the presented case indicate that greater customizability of threshold and alert settings would be beneficial for user groups with glycemic instability other than people with diabetes, and for hospitalized infants in particular. Further potential use cases may include children of mothers with gestational diabetes, children with metabolic disorders, children with neonatal diabetes mellitus, preterm infants, and infants with difficulties in enteral feeding.

\section{Strengths and Limitations}

It is important to note that although rtCGM provides information about glucose dynamics and variability, these systems might be less accurate when it comes to direct comparison with point-of-care testing of blood glucose levels. In order to keep invasive diagnostics for the patient reduced to a minimum, there were not enough CBG data points available to allow for a robust calculation of the mean absolute relative difference. This limits our ability to evaluate the accuracy of rtCGM readings, particularly of glucose levels $<40 \mathrm{mg} / \mathrm{dL}$. As rtCGM systems correlate the electric signal of the sensor with interstitial glucose concentrations in a linear fashion, they are not designed to detect the low glucose levels that occur in newborn infants after birth. Moreover, alert settings are not fully customizable to threshold 
values that seem reasonable to use in infants, who have a much lower physiological glucose range compared to older children and adults [9].

The app xDrip+, which was used in this case study, originates from an online community of people living with type 1 diabetes. The Android application package needed for setup, the app's source code, and instructions on how to install and use the app are openly available on the internet. Recently, open-source rtCGM apps such as xDrip+ for Android phones [16] and Spike for Apple iOS [26] have become increasingly popular and are used by thousands of people in the worldwide type 1 diabetes community [27], especially by those living in countries where commercial rtCGM systems are not accessible or not reimbursed by the healthcare system [28]. Despite their popularity, so far neither of the aforementioned open-source rtCGM apps have been tested in clinical trials or been approved by a regulatory body. The creators of these apps and the online community around them publicly disclose that they should be used with caution at all times and at one's own risk. The controlled environment of a NICU was an ideal setting to observe outcomes and potential benefits of the off-label use while ensuring minimal risk for the patient at the same time. We found that the app was also a more suitable solution that best met the child's medical needs as well as healthcare professionals' and the caregivers' expectations on relevant alarms in case of glucose excursions. However, the safety and accuracy of xDrip+ as such has not been systematically investigated so far, and its use has only been described in conjunction with observational and self-reported data from open-source automated insulin delivery system users [29,30]. Further research on personal and off-label rtCGM use and differences between native and alternative algorithms in translating raw sensor data is needed, as well as customization of commercially available rtCGM systems.

\section{Conclusions}

The use of rtCGM can be considered in neonatal patients at risk of hypoglycemia, such as infants with transient or permanent $\mathrm{CHI}$, to reduce the frequency of blood glucose measurements and focus them on potential decision-making points. However, these devices have been designed to be used by people with diabetes and are currently not approved for use in children younger than 2 years of age. Other use cases, such as infants with glycemic instability and other patients with rare conditions that might benefit from continuous glucose monitoring, are currently not being addressed sufficiently by the medical device market. Further investigation on the use and accuracy of rtCGM in wider patient groups, as well as further customization of rtCGM systems, is needed to address unmet needs of wider population groups.

\section{Acknowledgments}

We would like to thank the developers of xDrip+ of the diabetes online community for their cooperation, helpful comments, and thorough review of the paper.

The caregivers gave their consent for the off-label use of xDrip+ and for the publication of this case study.

The authors received no financial funding for the research conducted. We acknowledge support from the German Research Foundation and the Open Access Publication Funds of Charité - Universitätsmedizin Berlin for the publication of this paper.

\section{Authors' Contributions}

$\mathrm{KB}, \mathrm{MW}$, and SH performed the literature search. KB, OB, and CB designed the study design and methods. KB, ML, DH, NJR, and SH collected the data. KB and MW performed the data analysis. KB wrote the initial draft for the paper. All authors have reviewed and revised the manuscript and have read and approved the final version of the paper.

\section{Conflicts of Interest}

All authors have completed the Unified Competing Interest form and declare the following: KB received research grants from the Berlin Institute of Health Junior Clinician Scientist and Digital Clinician Scientist program, the European Commission's Horizon 2020 Research and Innovation program, the Wellcome Trust, Stiftung Charite, and the German Diabetes Association. She has served as a speaker and advisory board member for Medtronic Diabetes and Hi.Health and received fees for medical consulting and public speaking from Roche Diabetes Care, Dexcom, Medtronic Diabetes, Diabeloop, BCG Digital Ventures, and Bertelsmann Stiftung; all outside the submitted work. MW reports research grants from the European Commission's Horizon 2020 Research and Innovation program outside the submitted work and was employed by Medtronic Diabetes Germany until 2018. TU reports research grants from the European Commission's Horizon 2020 Research and Innovation program outside the submitted work. ML received research grants from the Berlin Institute of Health and the Berlin Cancer Society outside the submitted work. CB is supported by the German Federal Department of Research and Education and has received lecture fees from Chiesi paid to his employer, both outside the submitted work. All other coauthors have no conflict of interest to declare.

\section{Multimedia Appendix 1}

Daily profiles of sensor glucose and therapeutic management of a newborn with transient CHI. Sensor glucose readings [mg/dL] are shown in blue, i.v. glucose distribution in green $[\mathrm{mg} / \mathrm{kg} / \mathrm{min}$ ) and s.c. glucagon infusion in orange $[\mu \mathrm{g} / \mathrm{kg} / \mathrm{h}]$. Low sensor glucose threshold (45 mg/dL) is shown in red. Capillary blood glucose (CBG) measurements are marked in magenta.

[DOCX File, 899 KB-Multimedia Appendix 1] 


\section{References}

1. Demirbilek H, Hussain K. Congenital Hyperinsulinism: Diagnosis and Treatment Update. J Clin Res Pediatr Endocrinol 2017 Dec 30;9(Suppl 2):69-87 [FREE Full text] [doi: 10.4274/jcrpe.2017.S007] [Medline: 29280746]

2. Arnoux J, de Lonlay P, Ribeiro M, Hussain K, Blankenstein O, Mohnike K, et al. Congenital hyperinsulinism. Early Hum Dev 2010 May;86(5):287-294. [doi: 10.1016/j.earlhumdev.2010.05.003] [Medline: 20550977]

3. Ludwig A, Enke S, Heindorf J, Empting S, Meissner T, Mohnike K. Formal Neurocognitive Testing in 60 Patients with Congenital Hyperinsulinism. Horm Res Paediatr 2018;89(1):1-6. [doi: 10.1159/000481774] [Medline: 29151084]

4. Muukkonen L, Männistö J, Jääskeläinen J, Hannonen R, Huopio H. The effect of hypoglycaemia on neurocognitive outcome in children and adolescents with transient or persistent congenital hyperinsulinism. Dev Med Child Neurol 2019 Apr;61(4):451-457 [FREE Full text] [doi: 10.1111/dmcn.14039] [Medline: 30246438]

5. Minakova E, Chu A. Congenital Hyperinsulinism. Pediatr Ann 2017 Nov 01;46(11):e409-e414. [doi: 10.3928/19382359-20171020-01] [Medline: 29131920]

6. AWMF. Diagnostik und Therapie des Kongenitalen Hyperinsulinismus (KHI). AWMF Leitlinien. URL: https://www. awmf.org/uploads/tx szleitlinien/174-0121 S1 Diagnostik-Therapie-Kongenitaler-Hyperinsulinismus-KHI 2020-01.pdf [accessed 2020-06-20]

7. Beardsall K, Thomson L, Elleri D, Dunger DB, Hovorka R. Feasibility of automated insulin delivery guided by continuous glucose monitoring in preterm infants. Arch Dis Child Fetal Neonatal Ed 2020 May;105(3):279-284. [doi: 10.1136/archdischild-2019-316871] [Medline: 31399480]

8. Galderisi A, Lago P, Steil GM, Ghirardo M, Cobelli C, Baraldi E, et al. Procedural Pain during Insertion of a Continuous Glucose Monitoring Device in Preterm Infants. J Pediatr 2018 Sep;200:261-264.e1. [doi: 10.1016/j.jpeds.2018.03.040] [Medline: 29861315]

9. Mola-Schenzle E, Staffler A, Klemme M, Pellegrini F, Molinaro G, Parhofer KG, et al. Clinically stable very low birthweight infants are at risk for recurrent tissue glucose fluctuations even after fully established enteral nutrition. Arch Dis Child Fetal Neonatal Ed 2015 Mar;100(2):F126-F131. [doi: 10.1136/archdischild-2014-306168] [Medline: 25381093]

10. Ogilvy-Stuart AL, Beardsall K. Management of hyperglycaemia in the preterm infant. Arch Dis Child Fetal Neonatal Ed 2010 Mar;95(2):F126-F131. [doi: 10.1136/adc.2008.154716] [Medline: 20231218]

11. McKinlay CJD, Chase JG, Dickson J, Harris DL, Alsweiler JM, Harding JE. Continuous glucose monitoring in neonates: a review. Matern Health Neonatol Perinatol 2017;3:18 [FREE Full text] [doi: 10.1186/s40748-017-0055-z] [Medline: 29051825]

12. Conrad SC, Mastrototaro JJ, Gitelman SE. The use of a continuous glucose monitoring system in hypoglycemic disorders. J Pediatr Endocrinol Metab 2004 Mar;17(3):281-288. [doi: 10.1515/jpem.2004.17.3.281] [Medline: 15112904]

13. Rayannavar A, Elci OU, Mitteer L, De León DD. Continuous Glucose Monitoring Systems: Are They Useful for Evaluating Glycemic Control in Children with Hyperinsulinism? Horm Res Paediatr 2019;92(5):319-327. [doi: 10.1159/000506230] [Medline: 32208390]

14. Saif M, Kapoor A, Kochar IPS, Jindal R. Continuous glucose monitoring system for congenital hyperinsulinemia. Indian Pediatr 2013 Apr;50(4):421-422 [FREE Full text] [doi: 10.1007/s13312-013-0103-3] [Medline: 23665604]

15. Alsaffar H, Turner L, Yung Z, Didi M, Senniappan S. Continuous Flash Glucose Monitoring in children with Congenital Hyperinsulinism; first report on accuracy and patient experience. Int J Pediatr Endocrinol 2018;2018:3 [FREE Full text] [doi: 10.1186/s13633-018-0057-2] [Medline: 29599801]

16. Github - xDrip Plus. URL: https://github.com/NightscoutFoundation/xDrip [accessed 2020-06-20]

17. Yap KL, Johnson AEK, Fischer D, Kandikatla P, Deml J, Nelakuditi V, et al. Congenital hyperinsulinism as the presenting feature of Kabuki syndrome: clinical and molecular characterization of 9 affected individuals. Genet Med 2019 Jan;21(1):233-242. [doi: 10.1038/s41436-018-0013-9] [Medline: 29907798]

18. Hoermann H, El-Rifai O, Schebek M, Lodefalk M, Brusgaard K, Bachmann N, et al. Comparative meta-analysis of Kabuki syndrome with and without hyperinsulinaemic hypoglycaemia. Clin Endocrinol (Oxf) 2020 Jun 13:346-354. [doi:

10.1111/cen.14267] [Medline: 32533869]

19. Nally LM, Bondy N, Doiev J, Buckingham BA, Wilson DM. A Feasibility Study to Detect Neonatal Hypoglycemia in Infants of Diabetic Mothers Using Real-Time Continuous Glucose Monitoring. Diabetes Technol Ther 2019 Apr;21(4):170-176. [doi: 10.1089/dia.2018.0337] [Medline: 30839229]

20. Pinchefsky EF, Hahn CD, Kamino D, Chau V, Brant R, Moore AM, et al. Hyperglycemia and Glucose Variability Are Associated with Worse Brain Function and Seizures in Neonatal Encephalopathy: A Prospective Cohort Study. J Pediatr 2019 Jun;209:23-32. [doi: 10.1016/j.jpeds.2019.02.027] [Medline: 30982528]

21. Tomotaki S, Toyoshima K, Shimokaze T, Kawai M. Reliability of real-time continuous glucose monitoring in infants. Pediatr Int 2019 Oct;61(10):1001-1006. [doi: 10.1111/ped.13961] [Medline: 31287607]

22. Cumberpatch AR, Weston PJ, Harding JE, Harris DL. Parents of babies who participated in an invasive clinical study report a positive experience: the Glucose in Well Babies (GLOW) study. Arch Dis Child Fetal Neonatal Ed 2020 Jan;105(1):4-7. [doi: 10.1136/archdischild-2019-317417] [Medline: 31666312] 
23. Harris DL, Weston PJ, Gamble GD, Harding JE. Glucose Profiles in Healthy Term Infants in the First 5 Days: The Glucose in Well Babies (GLOW) Study. J Pediatr 2020 May 04:34-41. [doi: 10.1016/j.jpeds.2020.02.079] [Medline: 32381469]

24. Saw H, Yao N, Chiu C, Chen J. The value of real-time continuous glucose monitoring in premature infants of diabetic mothers. PLoS One 2017;12(10):e0186486 [FREE Full text] [doi: 10.1371/journal.pone.0186486] [Medline: 29036213]

25. McKinlay CJD, Alsweiler JM, Ansell JM, Anstice NS, Chase JG, Gamble GD, CHYLD Study Group. Neonatal Glycemia and Neurodevelopmental Outcomes at 2 Years. N Engl J Med 2015 Oct 15;373(16):1507-1518 [FREE Full text] [doi: 10.1056/NEJMoa1504909] [Medline: 26465984]

26. Spike: Get the most out of your CGM. Spike. URL: https://github.com/SpikeApp/Spike [accessed 2020-06-20]

27. Lee JM, Newman MW, Gebremariam A, Choi P, Lewis D, Nordgren W, et al. Real-World Use and Self-Reported Health Outcomes of a Patient-Designed Do-it-Yourself Mobile Technology System for Diabetes: Lessons for Mobile Health. Diabetes Technol Ther 2017 Apr;19(4):209-219. [doi: 10.1089/dia.2016.0312] [Medline: 28245152]

28. Pfiester E. Cost and Rationing of Insulin and Diabetes Supplies: Findings from the T1International Patient Survey. T1International. URL: https://www.t1international.com/media/assets/file/ T1International Report - Costs and Rationing of Insulin Diabetes Supplies 2.pdf [accessed 2020-06-23]

29. Petruzelkova L, Soupal J, Plasova V, Jiranova P, Neuman V, Plachy L, et al. Excellent Glycemic Control Maintained by Open-Source Hybrid Closed-Loop AndroidAPS During and After Sustained Physical Activity. Diabetes Technol Ther 2018 Dec;20(11):744-750. [doi: 10.1089/dia.2018.0214] [Medline: 30285476]

30. Braune K, O'Donnell S, Cleal B, Lewis D, Tappe A, Willaing I, et al. Real-World Use of Do-It-Yourself Artificial Pancreas Systems in Children and Adolescents With Type 1 Diabetes: Online Survey and Analysis of Self-Reported Clinical Outcomes. JMIR Mhealth Uhealth 2019 Jul 30;7(7):e14087 [FREE Full text] [doi: 10.2196/14087] [Medline: $\underline{31364599]}$

\author{
Abbreviations \\ CBG: capillary blood glucose \\ CHI: congenital hyperinsulinism \\ ICU: intensive care unit \\ isCGM: intermittently scanned continuous glucose monitoring \\ NICU: neonatal intensive care unit \\ rtCGM: real-time continuous glucose monitoring
}

Edited by G Eysenbach; submitted 12.07.20; peer-reviewed by K Gajewska, M Clements; comments to author 16.08.20; revised version
received 15.09.20; accepted 26.10.20; published 04.12.20
Please cite as:
Braune K, Wäldchen M, Raile K, Hahn S, Ubben T, Römer S, Hoeber D, Reibel NJ, Launspach M, Blankenstein O, Bührer C
Open-Source Technology for Real-Time Continuous Glucose Monitoring in the Neonatal Intensive Care Unit: Case Study in a Neonate
With Transient Congenital Hyperinsulinism
J Med Internet Res 2020;22(12):e21770
URL: $\underline{\text { http://www.jmir.org/2020/12/e21770/ }}$
doi: $10.2196 / 21770$
$P M I D: \underline{33275114}$

CKatarina Braune, Mandy Wäldchen, Klemens Raile, Sigrid Hahn, Tebbe Ubben, Susanne Römer, Daniela Hoeber, Nora Johanna Reibel, Michael Launspach, Oliver Blankenstein, Christoph Bührer. Originally published in the Journal of Medical Internet Research (http://www.jmir.org), 04.12.2020. This is an open-access article distributed under the terms of the Creative Commons Attribution License (https://creativecommons.org/licenses/by/4.0/), which permits unrestricted use, distribution, and reproduction in any medium, provided the original work, first published in the Journal of Medical Internet Research, is properly cited. The complete bibliographic information, a link to the original publication on http://www.jmir.org/, as well as this copyright and license information must be included. 